\title{
Experiential learning in physical therapy education
}

\section{Susan N Smith \\ Amy F Crocker}

School of Physical Therapy, University of the Incarnate Word, San Antonio, TX, USA
Correspondence: Susan N Smith University of the Incarnate Word, 430 I Broadway, CPO 4I2, San Antonio, TX 78209, USA

Tel + I 2102836913

Fax + I 2102836475

Email snsmith@uiwtx.edu
This article was published in the following Dove Press journal:

Advances in Medical Education and Practice

28 June 2017

Number of times this article has been viewed

Background and purpose: Experiential learning can provide students in entry-level physical therapy (PT) education programs the opportunity to practice skills and techniques, learned in the classroom, in a real-world setting. Experiential learning is currently being utilized in all entry-level PT programs in the form of professional practice experiences but may be integrated throughout the curriculum to enhance student engagement and knowledge application and retention. The purpose of this paper is to express the need for increased integration of experiential learning into entry-level PT education curricula.

Position and rationale: Experiential learning can effectively replace a portion of in-class laboratory time in entry-level PT education programs. Several methods of experiential learning exist, including simulation, integrated clinical experiences, service learning, community patient resource groups, and professional practice opportunities. Students benefit from the ability to practice hands-on skills in a safe, nonjudgmental environment. Students can still experience consequences of poor decisions but can have multiple opportunities to master the skill without the fear of negative outcomes. Incorporation of high-risk age ranges and diagnoses can be achieved through simulation.

Discussion and conclusion: Experiential learning can be integrated into any PT curriculum if faculties are committed and flexible. Experiential learning may be particularly useful in specialty practice areas where there are fewer opportunities for students to practice skills. The practice of reflection upon experiences that is commonly performed in conjunction with experiential learning will help prepare students for the type of reflective practice that is essential to transition from novice to expert practitioners.

Keywords: simulation, integrated clinical experience, service learning, clinical education, professional practice experience, professional practice opportunity

\section{Introduction}

Experiential learning provides learners an opportunity to practice skills and techniques learned in the classroom in a real-world or practical setting. The benefits of experiential learning have long been held in high regard and include enhancing understanding of content and improvement in interpersonal skills. ${ }^{1}$ In entry-level physical therapy (PT) education, professional practice experiences (PPEs) are the primary mode of experiential learning. The Commission on Accreditation in Physical Therapy Education (CAPTE) requires that at least 30 weeks of the program are dedicated to clinical education which includes PPEs. ${ }^{2}$ The majority of PPEs occur after the didactic portion of the program has been completed but may be interspersed as the program sees fit. Including experiential learning in the didactic component of a program, not included 
within PPEs, has been shown to be beneficial to student learning, but how much and when continue to be topics of intense discussion. ${ }^{3}$ With the push to decrease course hours and overall length of PT education programs, it is important to ascertain whether the integration of experiential learning into a program could increase efficiency by allowing students the opportunity to gain clinical and reasoning skills sooner within the program.

Many PT education programs introduce experiential learning through community service by participation in faculty- or student-run clinics. Integrating PT students into the community has been shown to allow them to feel more connected to their community, and students have reported an improvement in cultural competence due to their participation. ${ }^{3}$ Can other skills be learned through experiential learning, therefore, decreasing the time students must spend in a laboratory setting? Typically, laboratory time includes acquisition and practice of skills necessary for the performance of PT examination and intervention including, but not limited to, palpation, tests and measures, manual therapy, and therapeutic exercise. Students often practice on their peers under the guidance of their instructors. Laboratories typically consist of several treatment mats/plinths and various types of equipment to aid in student learning. The environment is not intended to replicate a patient treatment area. While simulation allows for repetition of competencies until mastery occurs, experiential learning does not afford this opportunity. ${ }^{4}$ Could a mix of simulation and experiential learning be used to replace a portion of laboratory time?

The benefits of experiential learning in PT education are well documented, but many questions remain., ${ }^{3,5}$ Can experiential learning in PT education programs adequately replace hands-on laboratory learning opportunities? Are the benefits of experiential learning limited to specific areas of study such as orthopedics or geriatrics? Are the logistics of integrating experiential learning a hindrance? Further research into the use of experiential learning in PT, as well as other health professions, may provide greater insight into how it can be used most efficiently and potential gains that can be made through experiential learning.

\section{Purpose}

The purpose of this paper is to express the need for increased integration of experiential learning into entry-level PT education curricula. This paper gives an explanation of experiential learning, and its use in PT and other health professions education, and discusses how further research could provide greater insight into how experiential learning could be used to not only improve student outcomes but also decrease inclass laboratory time.

\section{Position and rationale}

Our position is that experiential learning should be integrated throughout the didactic portion of entry-level PT curricula. We feel that experiential learning may replace portions of in-class laboratory time and lead to increased student confidence and improve PPE outcomes. To support our position, we discuss various methods, components, and outcomes of experiential learning. A discussion of potential barriers to implementation and areas of need for further research follows.

\section{Methods of experiential learning}

Implementation of experiential learning varies significantly across PT curricula. Some experiential learning methods are time and labor intensive, while others are less so. Cost, feasibility, time constraints, and course outcomes play a role in determining which methods work best for a particular course or program.

\section{Simulation}

Use of mock or computerized patients is not a new concept in PT education. Simulation has been used for decades to assist with skill acquisition and assessment. The ability to practice a skill until mastery is one of the many benefits to the use of simulation. ${ }^{4,6,9}$ Fidelity is the key to effective simulation as it is important that the simulated patient appears and behaves as a "real" patient would. This issue can be managed through thorough training of simulated patients and various electronic controls in computerized patients. If a simulation is effective, students will have the opportunity to experience, reflect, develop new ideas based on the experience, and plan for future experiences. ${ }^{5}$ The use of simulation during academic preparation for intensive care unit experiences was found to be particularly useful, as students were not hindered by the fear of harming a patient in the process of their practice. ${ }^{6}$

Live patients can participate in training, and computerized patients can be programmed to act through various patient care scenarios. Often the scenarios are based on real patient cases, and patients can be progressed along a continuum of care rather quickly, something that is not possible in a traditional clinical setting. Simulation staff must be intimately familiar with the patient case and fully understand the objectives of the experience. ${ }^{6}$ Several studies used real patient cases as the foundation for their patient simulations, and some even used videotapes of patient interactions to aid 
in training simulated patients. ${ }^{8}$ Watson et $\mathrm{al}^{8}$ performed two parallel randomized controlled trials using simulated patients to determine whether the use of simulated patients could replace a portion of clinical time or PPEs in a physiotherapy program. The result was that up to $25 \%$ of the clinical time could be replaced with simulated patients without it being at a detriment to the student. ${ }^{8}$ The greatest limitation noted by Watson et $\mathrm{al}^{8}$ was the inability to replicate the physical presentation of a patient.

In its early years, simulation was limited to live "actors" portraying patient scenarios. ${ }^{4}$ Recent advances in computer technology allow computerized patients to be programmed to depict realistic responses. Some of the benefits noted by Bednarek et $\mathrm{al}^{9}$ include "feedback during or after the experience, an opportunity for repetitive practice [...] a range of difficulty in skill levels available [...] representation of clinical variation, a controlled environment $[\ldots]$ and the degree of realism the experience provides" (p. 27). The use of high-fidelity simulation (HFS) has been beneficial in teaching acute care and cardiopulmonary content, as these are areas that students tend to have the least self-confidence and minimal PPE opportunities exist in these settings. After participating in HFS training, students presented with increased self-efficacy and interest in pursuing a career in acute care or cardiopulmonary settings. ${ }^{7}$ HFS can be used to meet a variety of course objectives including mastery of communication skills, response to high-risk patient scenarios, and progression of a patient's plan of care.

\section{Integrated clinical experiences}

Integrated clinical experiences (ICEs) allow early exposure of students to patients/clients. There are numerous methods of ICE integration, but most include up to eight to ten students per faculty clinical educator. ${ }^{10}$ PPEs most often employ a $1: 1$ or 2:1 student-to-clinical instructor ratio. The purpose of ICEs is to allow exposure to patient care and sometimes include the acquisition of skills or refinement of practice. ICEs can often be achieved through a pro bono faculty or student-run clinic, and clinical observations. ICEs are most commonly used as a precursor to PPEs and allow students to develop psychomotor skills in a supervised setting. ${ }^{10}$ One of the benefits of ICE is authentic patient/client interaction as students must learn to adapt to patient and caregiver responses. ICE provides opportunities for "self-assessment [...] skill development and professional growth" (p. 13). ${ }^{11}$ Faculty traditionally serve as clinical educators in ICE scenarios, but high-quality clinical sites and clinical instructors may also serve as educational partners. ICE may increase accountability in the classroom, as students will be expected to demonstrate skills shortly after acquisition in class.

At the University of the Incarnate Word (UIW) School of Physical Therapy, students participate in a community clinic for six consecutive semesters starting in the first semester of the program. Students provide PT services under the direction of licensed physical therapists. Patients/clients are referred to the UIW clinic from local low-cost or free clinics, other PT clinics if they continue to require skilled care beyond the limits of their health care coverage, and primary care facilities. Students perform the majority of the care provided; this allows students to apply skills they are learning in the classroom in a real-life setting shortly after skill acquisition.

\section{Service learning}

Service learning is not merely volunteering. Service learning is a "mutually beneficial process that affects both the recipients and the providers of care" (p. 95). ${ }^{12}$ Schools integrate service learning into their curricula through health fairs, community education, and community clinics. Students learn not only how to apply their clinical skills but also how to advocate for health promotion and collaborate with community partners to provide the best possible outcome for their clients. The opportunities that service learning provides are unique but limited, as often clients are only encountered during one event and may not be seeking longer-term care, or follow-up may not be available. Benefits of participation in service learning far exceed the potential benefits of experiential learning alone and provide a framework for students to continue to participate in service activities following graduation.

\section{Community patient resource group}

Community patient resource group (CPRG) is a unique method of bringing patients/clients and students together. CPRG was introduced by the University of Indianapolis and consists of a group of individuals in the community who have various diagnoses and have agreed to partner with the university to volunteer as "patients" for students in the university's PT program. ${ }^{13}$ The group participates at various times throughout the year to provide students with the opportunity to assess real "patients" who match the diagnoses or patient populations students are learning about. Kelly and King $^{13}$ found that both faculty and students viewed the CPRG positively and found its participation beneficial, especially in the area of learning professional values, and when learning about neurological diagnoses. Cost and management are two potential barriers to CPRGs, as in the original model, patients were compensated for their time and provided with 
transportation vouchers, and a yearly gathering was planned and paid for by the University.

\section{Professional practice opportunity}

Professional practice opportunity (PPO) is similar to ICE but more guided. Students are required to visit two to four clinical sites, complete an assignment related to the experience, and reflect upon the treatment observed for at least one patient. The intent is for students to perform "interactive clinical observations, education, and research" (p. 60). ${ }^{14}$ While the focus is not skill acquisition, students practice their interpersonal skills, and may experience gains in that area. Students are exposed to a wide variety of patients and can gain a greater appreciation for the patient's lived experience. This method can be particularly useful in settings that typically are not open to hands-on student experiences, such as neonatal intensive care units and cardiac rehabilitation settings. Students who are particularly interested in those areas can still get a sense of how care is provided in those units and potentially meet professionals in those fields who may be able to serve as mentors.

\section{Components of experiential learning}

While there are many different methods of experiential learning, some commonalities exist among the components of each.

\section{Early practice, and growth in affective and psychomotor domains}

Unlike most PPEs, experiential learning can be integrated into the didactic portion of PT curricula from the beginning of the program. Affording students the opportunity to practice the skills they have learned shortly after initial contact with the material helps solidify the content and provides context for their learning. ${ }^{3}$ Often students initially feel more comfortable performing hands-on skills such as physical examination versus soft skills such as patient interview and management. Early patient exposure provides students an opportunity to practice their "affective, psychomotor, and cognitive skills in a supervised setting" (p. 25). ${ }^{10}$

\section{Feedback}

Feedback can be immediate and shape future performance. Different methods of experiential learning can provide immediate feedback that can influence the students to change their performance. When students make an error during a simulation, instructors can immediately pause or stop the experience, correct the error, and allow students to practice the skill until they achieve mastery. Providing immediate correction is not always a possibility outside of simulation. During ICEs, service learning, CPRGs, and PPOs, feedback can be provided by peers, clinical educators, and patients/ clients. Feedback may be given during or after the experience and may be formal or informal. Immediate feedback is often provided when a student is making an error in performance or when patient/client care may be compromised. The clinical educator can provide feedback that prompts a change in performance or behavior and allows the student the opportunity to reflect upon the feedback provided and make appropriate modifications. The likelihood of identifying gaps in knowledge and errors in performance is greater when experiential learning exists within the didactic portion of PT education versus waiting until after the didactic portion. ${ }^{5}$ When students have received feedback on their performance, they are more confident in their skills and anxiety decreases. ${ }^{5}$

\section{Active learning}

Experiential learning requires that students apply knowledge to novel experiences. The students must engage in higherorder thinking and be active participants in their learning process. Gilbert et $\mathrm{al}^{15}$ found that students who were engaged in active learning showed significant improvement in their self-ratings of application of classroom knowledge and knowledge of the topic area. Simulation, ICEs, service learning, CPRGs, and PPOs facilitate active learning as students must activate and integrate prior knowledge to engage in the learning activity. While many PT programs are attempting to include teaching methods that encourage active learning, the majority still use lecture as the primary mode of content delivery. Experiential learning can be an adjunct to lecture, or other passive delivery methods, to incorporate active learning into PT curricula.

\section{Safe nonjudgmental environment}

By removing the pressure that is inherent to PPEs, experiential learning allows students to make mistakes in a low-stakes environment. Providing students a safe place to practice skills has proven to increase self-efficacy, confidence, clinical reasoning, and the ability to multitask in complex environments. ${ }^{7}$ During computer simulation activities, there is no risk of causing harm to a patient. Students can still experience consequences of poor decisions but can have multiple opportunities to master the skill without the fear of long-term effects. This environment may be especially beneficial when students are learning skills specific to acute care or a cardiovascular environment. Due to the amount 
of supervision that is provided, other experiential learning methods including ICEs, service learning, CPRGs, and PPOs provide opportunities for students to practice skills in an environment that fosters growth and refinement of skills while allowing students to make mistakes without severe consequences.

\section{Reflection and self-evaluation}

Traditional methods of instruction typically provide minimal opportunities for students to receive feedback on interpersonal and communication skills. Experiential learning provides multiple opportunities for feedback on these skills as students practice in novel situations with peers and patients/clients in a supervised setting. Students are often prompted to reflect upon feedback and evaluate their performance. Intentional reflection during professional formation allows students to build skills that will lead toward reflective practice. Instructors can promote reflection and self-evaluation through assignments linked to experiential learning activities. Skinner et $\mathrm{al}^{16}$ found that when physiotherapy students were provided with opportunities for "practice, reflection, self-evaluation and feedback" (p. 1), their confidence and interpersonal skills improved. They also noted that even in groups that specifically focused on interpersonal skills, students still scored lower in these areas of practice than others, indicating the need for more intense focus on interpersonal skills training in PT programs. The most effective method for interpersonal skills training was found to be experiential learning. ${ }^{17}$

\section{Outcomes of experiential learning}

While there are several methods of experiential learning, each affects change in common outcomes to varying degrees.

\section{Confidence}

Increased confidence is a common theme among all methods of experiential learning. Students gain confidence in their ability to provide quality care, interact with patients one-on-one, and participate in health advocacy. ${ }^{6,9}$ This confidence provides students a solid platform for future patient interactions, most notably their PPEs. Patients are often aware of a student's lack of confidence, and the student and patient experience may be affected. Increasing confidence before PPEs may allow students to spend time focusing on skill acquisition and mastery versus communication skills during PPEs.

\section{Student satisfaction}

Student satisfaction has been found to be overwhelmingly high for simulation activities with $98 \%$ of students stating that the simulation activities were valuable and reinforced what they learned in the classroom. ${ }^{6}$ Student satisfaction tends to drive student engagement. When students are engaged, their retention of knowledge also increases. ${ }^{6}$

\section{Exposure to various age ranges and diagnoses}

Through simulation, high-risk age ranges and diagnoses can easily be incorporated into PT curricula. Patients with complex presentations can be the subject of simulations, ensuring that students must practice skills, such as physiological monitoring, while in a low-stakes environment. ${ }^{18}$ For the experience to be the most meaningful, assessment must focus on reflection, linking new and old knowledge, and interactive clinical reasoning. The number of PPEs is often limited, and students are usually encouraged not to request specialty clinics unless they are certain that is the field of care where they desire to ultimately practice. Experiential learning does not present with any of these limitations and may allow for a greater variety of learning experiences.

Pritchard et $\mathrm{al}^{19}$ found that there was no significant difference between the use of simulated patients and other educational strategies when evaluating clinical practice competencies. The authors did concede that further studies need to be performed to adequately address the effects of experiential learning.

\section{Discussion}

Experiential learning can be integrated into any PT curriculum if faculties are committed and flexible. The introduction of experiential learning early in the curriculum can allow students to start building confidence, especially in their interpersonal skills, before formal PPEs, and be better able to thrive in PPEs without having to worry as much about their psychosocial skills. Promoting reflection upon experiences early in their PT education will prepare them for the reflection on practice that is required to transition from novice to expert practitioner. ${ }^{20}$

The greatest benefit may be in the use of experiential learning for high-risk patient scenarios. Specialty areas are often not readily available for PPEs, and students may be unable to pursue specialty practice immediately following graduation due to a lack of clinical experience. Experiential learning through simulation, HFS, CPRGs, and PPOs may provide exposure to specialty areas in a safe, non-threatening environment that allows the student an opportunity to practice hands-on skills without having to carry the cognitive load of ensuring patient safety or efficacy of care.

The amount of experiential learning used while teaching pediatric content in PT programs varies significantly 
throughout the US from 0 to 70 hours. ${ }^{21}$ It is reasonable to assume that the same variance may exist in other content areas within PT education. The wide range of hours devoted represents many factors, including the feasibility of including experiential learning, institutional resources, and instructor of record preferences. The lack of research in this area presents an opportunity for research into the optimal use of experiential learning.

More studies need to be performed to assess the cost of experiential learning and its feasibility for PT education programs. ${ }^{19}$ While cost varies among the different methods of experiential learning, the benefits are so great that they cannot be ignored. Schools with access to simulation laboratories may have fewer barriers to implementing simulation or HFS, while schools with limited access to simulation laboratories may find ICE or PPO to be a more feasible option. Planning experiential learning experiences may require a significant time and energy commitment from the instructor to ensure that learning is meaningful and aligns with the course content.

In the authors' experience with development of a PT school, they found that the model of experiential learning with the least barriers to implementation was in the creation of CPRGs. Community members were eager to participate in the students' education and felt their contributions were a form of paying it forward and brought a sense of meaning to their situation. Student evaluations have consistently reported that experience with the CPRGs helped students apply and retain knowledge. Interaction with "real" patients/ clients increased students' confidence before the start of their PPEs. The primary challenge during the creation of PPOs was coordination between local service providers and students. Working with the provider and student schedules initially required significant effort, but once relationships were established and expectations were clarified, less effort was required globally. The most challenging endeavor was the creation of a community clinic to allow integration of ICEs throughout the curriculum. Since participation in the community clinic was integrated into the curriculum, students have had multiple opportunities to receive feedback on their interpersonal and patient care skills from both peers and faculty clinicians. Maintaining a community clinic requires ongoing administrative and faculty support, but provides an invaluable opportunity for students' personal and professional growth.

\section{Conclusion}

While the benefits of experiential learning have been well documented, what has not been determined is the best method or the minimum amount of exposure needed to achieve positive outcomes. Further studies are needed to compare different methods of experiential learning, centered around the same patient population, to extrapolate the small differences in student learning that occur. Experiential learning should be an essential component of entry-level PT education.

\section{Disclosure}

The authors report no conflicts of interest in this work.

\section{References}

1. Knecht-Sabres LJ. Experiential learning in occupational therapy: can it enhance readiness for clinical practice? J Exp Educ. 2013;36(1):22-36.

2. CAPTE portal PT standards evidence. 2016 [updated July 15, 2016]. Available from: http://www.capteonline.org/AccreditationHandbook/. Accessed January 25, 2017.

3. Kruger JS, Kruger DJ, Suzuki R. Assessing the effectiveness of experiential learning in a student-run free clinic. Pedagogy Health Promot. 2015;1(2):91-94.

4. Sabus C, Macauley K. Simulation in physical therapy education and practice: opportunities and evidence-based instruction to achieve meaningful learning outcomes. J Phys Ther Educ. 2016;30(1):3-13.

5. Mori B, Carnahan H, Herold J. Use of simulation learning experiences in physical therapy entry-to-practice curricula: a systematic review. Physiother Can. 2015;67(2):194-202.

6. Ohtake PJ, Lazarus M, Schillo R, Rosen M. Simulation experience enhances physical therapist student confidence in managing a patient in the critical care environment. Phys Ther. 2013;93(2):216-228.

7. Silberman NJ, Litwin B, Panzarella KJ, Fernandez-Fernandez A. High fidelity human simulation improves physical therapist student selfefficacy for acute care clinical practice. J Phys Ther Educ. 2015;29(4): $14-24$.

8. Watson K, Wright A, Morris N, et al. Can simulation replace part of clinical time? Two parallel randomised controlled trials. Med Educ. 2012;46(7):657-667.

9. Bednarek M, Downey P, Williamson A, Ennlat C. The use of human simulation to teach acute care skills in a cardiopulmonary course: a case report. J Phys Ther Educ. 2014;28(3):27-34.

10. Mai JA, Thiele A, O’Dell B, Kruse B, Vaassen M, Priest A. Utilization of an integrated clinical experience in a physical therapist education program. J Phys Ther Educ. 2013;27(2):25-32.

11. Hakim EW, Moffat M, Becker E, et al. Application of educational theory and evidence in support of an integrated model of clinical education. J Phys Ther Educ. 2014;28 (Suppl 1):13-21.

12. Fries K, Stewart JG. Partnering with those we serve: using experiential learning activities to support community nursing practice. Creat Nurs. 2012;18(3):93-97.

13. Kelly SP, King HJ. The community patient resource group: a novel strategy for bringing clinic to the classroom. J Phys Ther Educ. 2012;26(2): $32-40$.

14. Reicherter EA, Waller SM. Professional practice opportunities: preparing students to care for an aging population. J Phys Ther Educ. 2014;28(2):60-68.

15. Gilbert BL, Banks J, Houser JHW, Rhodes SJ, Lees ND. Student development in an experiential learning program. J Coll Student Dev. 2014;55(7):707-713.

16. Skinner KL, Hyde SJ, McPherson KBA, Simpson MD. Improving students' interpersonal skills through experiential small group learning. J Learn Des. 2016;9(1):21-36.

17. Parry RH, Brown K. Teaching and learning communication skills in physiotherapy: what is done and how should it be done? Physiotherapy. 2009;95(4):294-301. 
18. Smith N, Prybylo S, Conner-Kerr T. Using simulation and patient role play to teach electrocardiographic rhythms to physical therapy students. Cardiopulm Phys Ther J. 2012;23(1):36-42.

19. Pritchard SA, Blackstock FC, Nestel D, Keating JL. Simulated patients in physical therapy education: systematic review and meta-analysis. Phys Ther. 2016;96(9):1342-1353.
20. Jensen GM, Gwyer J, Shepard KF. Expert practice in physical therapy. Phys Ther. 2000;80(1):28-43.

21. Schreiber J, Moerchen VA, Rapport MJ, et al. Experiential learning with children: an essential component of professional physical therapy education. Pediatr Phys Ther. 2015;27(4):356-367.

\section{Publish your work in this journal}

Advances in Medical Education and Practice is an international, peerreviewed, open access journal that aims to present and publish research on Medical Education covering medical, dental, nursing and allied health care professional education. The journal covers undergraduate education, postgraduate training and continuing medical education including emerging trends and innovative models linking education, research, and health care services. The manuscript management system is completely online and includes a very quick and fair peer-review system. Visit http://www.dovepress.com/testimonials.php to read real quotes from published authors.

Submit your manuscript here: http://www.dovepress.com/advances-in-medical-education-and-practice-journal 